\title{
Balance in the Turbulent World of Economy
}

\author{
A. JAKIMOWICZ ${ }^{a}$ AND J. JUZWISZYN ${ }^{b}$ \\ ${ }^{a}$ Institute of Economics, Polish Academy of Sciences, \\ pl. Defilad 1, PL-00901 Warsaw, Poland \\ ${ }^{b}$ Department of Mathematics and Cybernetics, Wroclaw University of Economics, \\ Komandorska Street 118/120, PL-53345 Wrocław, Poland
}

\begin{abstract}
The stock market balance can be presented as a result of mutual effect of the supply and demand on the market. This creates high-frequency dynamics of prices for shares, what in turn leads to the appearance of the threedimensional rotary trajectories of the market. The 3-D space is a Cartesian product: prices, volumes, and time. In this space whirling vectors form rotary-spiral trajectories and, they in turn, determine in the appropriate time periods side surfaces of solids of revolution, which rotate as well. Perpendicular projections of rotary trajectories on planes with standing out time axis cause that economic rotary phenomena are depicted on the mentioned planes by means of flat zigzags. Double rotating of economic vectors resembles precession movement. This is the precession movement which guarantees oscillating-rotating vectors around the hypothetical line of economic balance. Economic vectors are always set in rotary motion mainly by stimulating the vectors of demand and supply. Dynamically changing volumes of the mentioned forces cause that permanent state of economic balance practically do not exist in market reality. In the modified by the authors cobwebbed model states of fragile balance are explained by means of precession and accompanying it nutation. The rotary movement occurs universally in our world. The effects of vortexes from the world of nature are extremely quickly reflected in changing in chaotic way forces of demand and supply which in turn are the main generators of economic vortexes. Then the relationship is unambiguous and can be expressed by a short general statement claiming that vortexes generate vortexes regardless of the environment in which they occur. The resemblance between the rotary trajectories observed in hydrodynamics and the stock market rotary-spiral trajectory was the inspiration of the work for creating the econophysical analogue of the so-called stock market Reynolds number $\left(R_{e}\right)$. The academic community has long sought a description of the phenomenon of turbulence in financial markets, and this article is an attempt to face this challenge. The original idea behind developing an economic equivalent of the Reynolds number was that market vectors of volumes, prices and time components can be treated as particles of a stream of liquid flowing through a pipe of a given cross-section. The Reynolds number, defined in this way, can be applied in research into the dynamics of stock exchange indices and, in particular, for the development of short-term warning forecasts. Additionally, it can be treated as a coefficient confirming (or rejecting) long-term stock market predictions.
\end{abstract}

DOI: 10.12693/APhysPolA.127.A-78

PACS: 89.65.Gh, 47.27.Jv, 47.15.G-, 47.35.-i, 47.32.C-, 01.65.+g

\section{Introduction}

Stock market unpredictability over time (e.g. of share prices) has been the subject of many studies. The first significant attempts to explain the unpredictability of a stock market time series were made by Henri Poincaré [1]. In 1900, L. Bachelier, Poincare's student, obtained a doctoral degree for his dissertation entitled "Théorie de la spéculation" [2]. The concept applied in this dissertation was that the above-mentioned unpredictability was of a stochastic nature. Bachelier assumes that the price change process is subject to a Gaussian distribution. Currently, one of such stochastic processes is referred to as the Wiener process (or Brownian motion).

The Brownian process satisfies the equation of diffusion. Bachelier determined price change probability by introducing a chain equation, currently referred to as the Chapman-Kolmogorov Eq. [3]. At this point, it should be also mentioned that this equation had been previously discovered by a Polish physicist, Marian Smoluchowski a researcher working on Brownian motions [4]. Poincaré, while examining the movement of a small body within the gravitational field of two large neighbours, also discovered a surprising phenomenon. It was proven that the movement of a small body may be unpredictable - chaotic [1]. In 1889, for his research Poincaré was awarded a prize established to honor the sixtieth birthday of Oscar II, King of Sweden and Norway [5-7].

The phenomenon of movement unpredictability had been previously observed in hydrodynamics. It was found that, under some circumstances, fluid that had so far been flowing in a regular (laminar) way may become turbulent, chaotic and unpredictable. In 1823, Navier wrote equations of motion for viscous fluids, today referred to as Navier-Stokes equations [8]:

$$
\frac{d \boldsymbol{v}}{d t}=\boldsymbol{F}-\frac{1}{\rho} \operatorname{grad} P+\vartheta \Delta \boldsymbol{v},
$$

where: $\boldsymbol{v}$ - fluid velocity, $t$ - time of fluid flow, $\rho-$ fluid density, $P$ - pressure, $\boldsymbol{F}$ - unit mass force, $\vartheta$ kinematic viscosity, $\Delta \boldsymbol{v}$ - Laplacian of fluid velocity. The Navier-Stokes equation is a nonlinear equation; we still do not know the full analytical solution of this equation. It is particularly important in these reflections, since it describes fully-developed turbulence, namely, turbulence corresponding to a high Reynolds number. 


\section{Reynolds number in hydrodynamics}

In 1883, the English scientist O. Reynolds, to some extent, solved the problem of transmission from a laminar into a turbulent flow [9-11]. He demonstrated that a change of fluid flow character could be determined with the use of a value of certain dimensionless number, today referred to as the Reynolds number $-R_{e}[12-13]$. We will briefly outline the genesis of this number.

An object moving through a fluid is under the influence of resisting forces, referred to as drag. After Reynolds, we can distinguish pressure drag $R$ and viscous $\operatorname{drag} T$. Based on a dimensional analysis, the following formulas were obtained [14]:

$$
\begin{aligned}
& R=C \frac{\rho v^{2}}{2} S, \\
& T=B \eta v l,
\end{aligned}
$$

where: $B$ and $C$ - dimensionless constants, $v-$ certain mean velocity of the fluid, $\rho$ - density of the fluid, $S$ cross-sectional area of the object, perpendicular to the direction of the fluid flow, $\eta$ - fluid viscosity, $l$ - linear dimension of the object.

For high velocities, pressure drag is much higher than the viscous drag, while for small velocities, viscous drag is much higher than the pressure drag. After Reynolds, let us examine the following quotient:

$$
\frac{R}{T}=\frac{C \rho v^{2} S}{2 B \eta v l} .
$$

Dividing the dimensionless factors and rounding their quotients to the value of one and assuming that $S=l^{2}$, we obtain a formula for Reynolds' dimensionless constant $R_{e}$ [14]:

$$
R_{e}=\frac{\rho v l}{\eta} \text {. }
$$

On the basis of the empirical research, it was found that if the examined fluid was water, then for:

$R_{e}<1000$ - fluid flow is laminar (stable), $1000<R_{e}<2000$ - fluid flow is unstable, $R_{e}>2000$ - fluid flow is turbulent.

Observation of time series concerning the prices of securities strengthens our conviction about their unpredictable nature. Since it may not be excluded that the financial market is subject to chaotic dynamics, it seems justified to construct the Reynolds number analogue for the financial markets [15]. While considering the Reynolds formula, we can notice fluid viscosity as one of its elements. Such a value is not found in financial mathematics. Therefore, relation (5) should be transformed to make it more useful from an economic point of view.

\section{Economic analogue of the Reynolds number}

A construction of the economic equivalent of the Reynolds number requires the application of two more relations. The fluid equation proposed by the outstanding Russian physicist, J. Frenkel, will be used [14]:

$$
\eta=\frac{f}{D}
$$

where $f$ is a constant in a unit of force, and $D$ is a diffusion coefficient. Additionally, the Smoluchowski equation (also referred to as the Einstein equation) will be useful, which expresses the relation between the diffusion coefficient and a variance determined in a time interval of duration $t$ :

$$
\sigma^{2}=2 D t
$$

As follows from Eq. (7), the Brownian process satisfies the diffusion equation. While finally substituting relations (6) and (7) to Eq. (4), we obtain:

$$
\begin{gathered}
R_{e}=\frac{\rho v^{2} S}{\eta v l}=\frac{\rho v^{2} S}{\frac{f}{D} v l}=\frac{D \rho v S}{f l}= \\
\frac{\sigma^{2} \rho v S}{2 f t l}=\frac{\sigma^{2} \rho v S}{2 f \frac{l}{v} l}=\frac{\sigma^{2} \rho v^{2} S}{2 f l^{2}} .
\end{gathered}
$$

It is known from Eq. (6) that $f=D \eta$. In case of determining the Reynolds number for one stock-listed company, both diffusion and viscosity are constant, and for this reason $f$ has been omitted from formula (8). Viscosity $\eta$ is treated then as a constant equal to 1 . On the other hand, when viscosity refers to a specific index, then its value grows with an increase in the number of companies making up the created stock exchange index. Diffusion is a constant value, proportional to the viscosity of the company with the highest viscosity value in the entire index. Time represents any length of time series. Therefore, according to Frenkel's approach, $f / v$ is a time variable quotient of force and velocity at which companies making up the stock exchange index are rotating (or the quotient of force and velocity at which one company, for which the stock exchange Reynolds rate is determined, is rotating). After assuming that the cross-section is equal to the square of the linear dimension $\left(S=l^{2}\right)$ and skipping the Frenkel constant $2 f$, we obtain a stock market analogue of the Reynolds number in the following form:

$$
R_{e}=\rho \sigma^{2} v^{2}=\rho(\sigma v)^{2},
$$

where $\rho$ represents density (constant number of companies making up the stock exchange index), $v$ is a certain mean velocity of the turbulent flow, while $\sigma^{2}$ is a volume variance. If $\rho=$ constans $=1$, then the formula is:

$$
R_{e}=(\sigma v)^{2} .
$$

The stock market analogue of the Reynolds number, expressed through the product of a volume variance and the square of stock market flow velocity, can be applied in a stock market technical analysis as the so-called Reynolds warning rate. The velocity of stock exchange movement is equal to the tangent of the angle of inclination of the volume regression line, established with the least squares method [16]. Determination of the threshold values of Reynolds rate for various types of markets and their later analysis may contribute to an increase in market predictability. Values of Reynolds warning rate are determined by periods in which the market demonstrates stable dynamics or turbulent dynamics. 
An economic equivalent of the Reynolds number (10) is a key element in the description of the phenomenon of turbulence in financial markets. It enables a new approach to business dynamics in the context of market predictability. Thus, anticipation of turning points can become an element of investment strategies.

\section{Rotational nature of securities market dynamics and the problem of balance}

If we examine the dynamics of stock exchange indices in three dimensions, i.e. in space $\boldsymbol{R}_{+}^{3}=P \times Q \times T$, where symbols $P, Q$ and $T$ are used to determine the value of index, volume and time, respectively, then we can observe that the behaviour of the stock exchange is described by a rotary-spiral trajectory. This confirms to certain degree the hypothesis on the chaotic nature of financial processes [17-19]. Figure 1 presents a spiral evolution of the WIG stock exchange index listed on the Warsaw Stock Exchange. It shows that stock exchanges rotate around a hypothetical path of balance and the trajectory resembles a line wound around a cone. The axes of those cones form a complicated, twisting line (often a broken line), which determines the level of balance in subsequent periods. As A. Smoluk observes, a rotational motion is the essence of economics and business cycles are unavoidable since they result from Newton's law and indicate a natural tendency of economic systems towards equilibrium [20-21].

In the economic system $\boldsymbol{R}_{+}^{3}=P \times Q \times T$ (index value, volume, time), vectors of components $\left(p_{i}, q_{i}, t_{i}\right) \in \boldsymbol{R}_{+}^{3}$, where $i \in N$, subject to demand and supply forces, move in precession and form rotational trajectories. Those trajectories determine (in appropriate time spans) rotary quadric surfaces. Examples of rotary quadric surfaces include: cones, elliptic cones, cylinders, elliptic, hyperbolic and parabolic cylinders, paraboloids, one- or twosheeted hyperboloids and ellipsoids [22]. All of the abovementioned lateral surfaces are regular and smooth surfaces. However, the three-dimensional economic vortex, as shown in Fig. 1, is not a trajectory which could be described as regular and smooth. But it certainly should be claimed that the economic rotational trajectory is fixed inside the above-mentioned rotary quadric surfaces. The purpose of model binding of those surfaces is only to serve as a geometric representation of a natural - irregular "sleeve", which is constantly woven by rotating vectors in economics.

Observations of time series in $\boldsymbol{R}_{+}^{3}=P \times Q \times T$ require a slightly broader discussion of the issue concerning the precession of the vector with components $\left(p_{i}, q_{i}, t_{i}\right)$. Cones determined by a trajectory in certain time intervals also reveal a tendency to rotate around a certain hypothetical line [23]. This kinematic phenomenon resembles a precession movement, which occurs when torgue with a component perpendicular to the angular momentum is applied to a body spinning around its axis. The axis of the body rotation then starts tilting from the

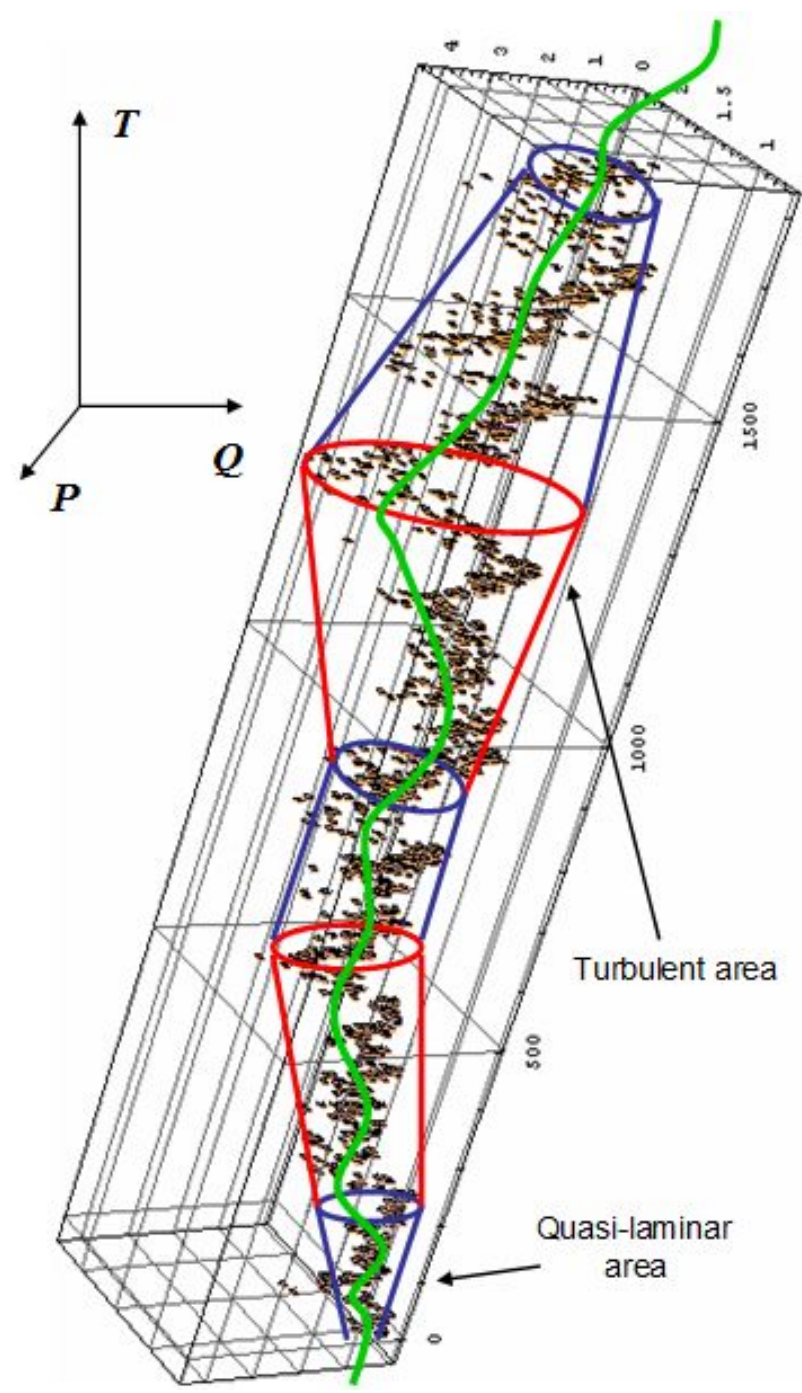

Fig. 1. Three-dimensional rotational trajectory of WIG index quoted on the Warsaw Stock Exchange, with truncated rotary quadric surfaces moving in precession in the period from 1994-04-18 to 2002-04-18 drawn in space $\boldsymbol{R}_{+}^{3}=P \times Q \times T$ (index value, volume, and time, respectively).

vertical position, thus making a movement that draws a surface in the shape of the lateral surface of a cone. Precession is responsible for the stability of spinning objects. Precession can be accompanied by nutation, in which case additional fluctuations or vibrations of the rotational axis of economic vectors result in sustaining the rotational movement of the body - in this case, the stock exchange. The mere fact of a precessive rotation of cones can be identified with states of general balance, while the axis of the cone determined by the rotational-spiral trajectory will be referred to as the temporary balance axis (observed in the time span in which the cone was determined). Generally, as an example of the precession movement, physicists provide the rotational movement of the Earth, where during the rotations of the planet 
around its own axis this axis tilts from the vertical position, as a result of which it draws a cone. The period of drawing a full galactic cone lasts about 25,600 years [24]. This represents the so-called Platonic year.

As it has been proven in this chapter, market vectors can be treated as particles of a liquid flow, and consequently, such a description of turbulence leads to a new definition of market balance. It includes two elements. A hypothetical line of dynamic balance should be distinguished (first element), around which the actual market vectors (second element) rotate. It must be emphasized that the dynamic balance line is a virtual construction, as it is never achieved, and it only provides a frame of reference for actual movements of economic vectors. Vortices formed around it can be smaller or larger, but they are always present, therefore distinguishing laminar and turbulent areas in Fig. 1 is just a matter of convention. If the stock exchange reached the hypothetical long-term equilibrium line, it would mean its liquidation, so this line is a repeller. When a sleeve created by rotary quadric surfaces in which vectors rotate is of a smaller diameter, we can talk about quasi-laminar areas, and when this diameter is larger, we are dealing with turbulent areas. Examples of quasi-laminar and turbulent areas are shown in Fig. 1.

\section{Explanation of the rotational movement of market vectors based on the theory of economics}

Let us look for a moment at the dynamics of vector adjustment to economic balance levels. Let us assume that in the economic three-dimensional space, vectors of various components are subject to market adjustment processes. On a plane, those processes are usually depicted with the use of graphs of polygonal functions (zigzags), where one of the vector components is always time. When we increase the dimension of space by one (by adding one vector component dependent on the previous one), then in the three-dimensional Cartesian coordinate system we generally obtain a rotational trajectory. The dependence of vector components $\boldsymbol{R}_{+}^{3}$ is very important here. An increase or a decrease in the value of one of the components always involves a decrease or an increase in the value of the other component of the vector. As examples of systems, in which we can observe such three-dimensional rotations, we should list the following relations: output volumes of minerals and their prices, volumes of mined natural resources and their value, volume of acquired species of timber and their price, volume of agricultural produces and food products and their prices, etc. Equally important are also examples of threedimensional rotations observed in the systems where both vector components are quantitative, e.g. changing populations of wolves and deer in the American Yellowstone National Park, or changing populations of foxes and common hare in Poland (before and after the introduction of mass vaccination of foxes against rabies, increase of agricultural mechanization, increase of traffic intensity, etc.).
All of the dynamic systems mentioned above, at the moment when a graphical three-dimensional analysis of their dynamics is made, show its rotational nature to the observer. If observations are two-dimensional, then vector rotations are apparently flat and their shape resembles a modified cobweb model.

Orthogonal projections of rotational trajectories onto planes create well-known zigzags seen on time charts representing the value of stock-exchange indices and volumes. The three transformations provided below present orthogonal projections of a rotational trajectory onto three planes perpendicular to one another.

$$
\begin{aligned}
& p: \boldsymbol{R}_{+}^{3} \rightarrow \boldsymbol{R}_{+}^{2}, \quad p:(P \times Q \times T) \rightarrow(P \times T), \\
& q: \boldsymbol{R}_{+}^{3} \rightarrow \boldsymbol{R}_{+}^{2}, \quad q:(P \times Q \times T) \rightarrow(Q \times T), \\
& s: \boldsymbol{R}_{+}^{3} \rightarrow \boldsymbol{R}_{+}^{2}, \quad s:(P \times Q \times T) \rightarrow(P \times Q) .
\end{aligned}
$$

In the first two transformations, $p$ and $q$, we obtain graphs of segment-polygonal functions (flat zigzags) and, as a result of implementing the third transformation, $s$, we receive a curve resembling a vortex - spiral.

If we assume that a two-dimensional system of coordinates illustrates values of the stock exchange index changing over time, then - regardless of the trend prevailing during the observation of the stock exchange the chart will show flat zigzags representing a growth or a decrease of the value of this index. It will also be true in case of a changing volume. Therefore, we can look at two different graphs (two different zigzags), which independently present the dynamics of changes in the stock exchange vector in two various systems of coordinates (in the system of the index value - time or volume time).

The observation of stock exchange dynamics as a vector with two components, i.e. index value and volume, is very difficult when analysing a large number of listings. In practice, certain rotational regularities are perceived only when the number of observations in the index volume system is low. In practice, for a large number of listings, the flat trajectories of the vector index values and volume components very densely overlap, creating an indecipherable picture. Perceiving any regularity in such a picture is simply impossible. The trajectory of the stock exchange looks substantially different when we increase by one dimension the space in which we make our observations. In a three-dimensional system, our flat trajectories are stretched in time (we can also say that flat kinematic trajectories are literally detached from the index value - volume plane), revealing their real, kinematically rotational nature [25-26].

An identical visual effect can be achieved when stretching (along the time axis, situated perpendicularly to the index value - volume plane) the cobweb model. In such a case, we create a truncated prism with a tetragonal basis with a screw line wound on the lateral surface of the prism. Most probably, at the end of 1920s and at the beginning of the $1930 \mathrm{~s}$, such three-dimensional 
experiments related to literal stretching of the cobweb mechanism were not carried out by four, presumably independent, creators and at the same time propagators of this model, namely: J. Tinbergen, U. Ricci, H. Schultz and A. Hanau [27-30]. If this was the case, then the model attempt to explain extrapolating adjustment of cyclic fluctuations of prices and amounts of produced goods to economic balance levels could already at that time have been directed towards the issue of threedimensional economic vortices. The proposed new definition of economic balance presented in this article is compatible both with Walras' hypothesis of the excess market demand as well as with Marshall's hypothesis of excess demand price [31-34].

The proposed new definition of economic balance includes a virtual broken (or twisting) line, representing a hypothetical long-term dynamic balance and rotation of real market vectors around it. The line of long-term balance is a repeller, since reaching it would mean the death of the stock exchange. In the three-dimensional Cartesian coordinate system, vectors with volume, index value and time components are constantly subject to an unpredictable rotational process. Trajectories determined by this process are irregular economic helices. They are similar to helices created by particles of flowing liquids or gases. The economic Reynolds number differentiates individual market states in view of their complexity.

\section{Rotational motion on the stock exchange and in hydrodynamics as an example of logical homology}

The value and volume of a given asset depend on many factors, such as the reaction of individual players or entire communities of investors. Some of them are of an impermanent, even speculative nature, while others operate in the long-term. A three-dimensional analysis of stock exchange indices and individual shares demonstrates an unusual, striking similarity, which indicates one type of prevailing movement. This movement changes locations of points in space $\boldsymbol{R}_{+}^{3}=P \times Q \times T$, determining at the same time a rotational-spiral three-dimensional curve. The analysis of market dynamics in $\boldsymbol{R}_{+}^{3}$ brings certain physical associations with hydrodynamic models. The type of movement made by the market in $\boldsymbol{R}_{+}^{3}$ is strikingly similar to the rotational movement of fluids. If we look at stock market helices in various time scales, we can quickly notice that rotations of lower time degrees (scales) cause rotations in higher scales. In other words, in three-dimensional stock market kinematics, vortices (helices) emerging in a micro-scale cause vortices in higher, meso- and macro scales. This irregular rotational process continues with the assumption that stock exchange transactions are constantly made. Let us imagine for a moment that each of the specified stock exchange securities is assigned unambiguously one colour. Observing in $\boldsymbol{R}_{+}^{3}=P \times Q \times T$ colourful stock exchange helices (e.g. in a one-minute scale), we can conclude that chaotic vibrations of vectors (stock exchange particles) move in a similar way to air, gas or water particles or of a liquid of viscosity comparable to the kinematic viscosity of water equal to $1 \mathrm{cSt}$ measured at $4{ }^{\circ} \mathrm{C}^{*}$. Kinematic liquid viscosity expresses the relation of dynamic viscosity of a given liquid to its density.

Comparison of the stock exchange phenomena to hydromechanical or aerodynamic phenomena is a good example of logical homologies, emphasizing the rotation of particles and shares (or indices) at the stock exchange [35]. When stock exchange helices take the shape of a spiral (logarithmic, hyperbolic or Archimedean), it is easier to make a short-term forecast concerning the development of economic market vectors. Rotational and spiral graphs confirm that the stock market analogue of the Reynolds number can be applied in a technical analysis as a stock-exchange Reynolds warning rate. For the above reasons, establishing the threshold values for various types of markets and their thorough analysis may contribute to an increase in market predictability. The values of stock market Reynolds warning rate would determine the moments in which the market transforms from stable price dynamics into the turbulent dynamics.

Development of an economic equivalent of the Reynolds number constitutes an important and innovative econophysical achievement, since it confirms the basis idea of econophysics, according to which physical and economic objects can have a common theory. This is a situation described in the language of general system theory as logical homologies.

\section{Verification of the prognostic possibilities of the stock exchange Reynolds number}

We present below two examples of verifying the Reynolds stock exchange rate for the WIG index quoted on the Warsaw Stock Exchange. The analysis of time series for two various periods confirmed the hypothesis of the warning nature of the stock exchange Reynolds number. In the calculations below, symbol $R_{e}$ (YYYY-MM-DD) denotes the value of the stockexchange Reynolds number as of (YYYY-MM-DD). Additionally, the periods for which the stock-exchange Reynolds number is determined always include the data from 29 subsequent daily listings at the Warsaw Stock Exchange. The first period included days from 1994-0103 to 1994-03-08, while the second period included days from 1995-02-16 to 1995-03-28. Tables 1 and 2 present days on which the Reynolds number reached the maximum values. In both periods under examination, after exceeding the maximum value $R_{e}$, a clear change of the trend was observed at the Warsaw Stock Exchange. In the first period, a bull market on the stock exchange ended on 1994-03-08, while in the second period it ended on 1995-03-28.

\footnotetext{
*1 cSt - unit of kinematic viscosity, 1 centistokes $1[\mathrm{cSt}]=1\left[\mathrm{~mm}^{2} / \mathrm{s}\right]$.
} 
TABLE I

TABLE II

Reynolds number for WIG index calculated in the period from 1994-01-03 to 1994-03-08.

\begin{tabular}{|c|c|c|c|}
\hline Item & $\begin{array}{c}\text { Date } \\
(Y Y Y Y-M M-D D)\end{array}$ & WIG & Volume \\
\hline 1 & 1994-01-03 & $13,044.8$ & $143,139.5$ \\
\hline 2 & 1994-01-04 & $13,345.5$ & $209,657.6$ \\
\hline 3 & 1994-01-06 & $13,233.9$ & $257,420.0$ \\
\hline 4 & $1994-01-10$ & $13,310.8$ & $196,358.0$ \\
\hline 5 & 1994-01-11 & $13,558.0$ & $151,026.1$ \\
\hline 6 & 1994-01-13 & $14,117.5$ & $265,945.0$ \\
\hline 7 & 1994-01-17 & $14,625.1$ & $294,689.3$ \\
\hline 8 & 1994-01-18 & $15,081.6$ & $256,137.0$ \\
\hline 9 & 1994-01-20 & $15,420.8$ & $342,265.0$ \\
\hline 10 & 1994-01-24 & $15,846.3$ & $296,007.5$ \\
\hline 11 & 1994-01-25 & $16,808.6$ & $292,545.0$ \\
\hline 12 & $1994-01-27$ & $18,218.3$ & $487,042.0$ \\
\hline 13 & 1994-01-31 & $16,881.0$ & $444,232.0$ \\
\hline 14 & 1994-02-01 & $15,227.9$ & $193,050.5$ \\
\hline 15 & 1994-02-03 & $14,871.5$ & $353,126.0$ \\
\hline 16 & 1994-02-07 & $16,137.5$ & $285,926.0$ \\
\hline 17 & 1994-02-08 & $16,817.9$ & $362,794.0$ \\
\hline 18 & 1994-02-10 & $17,300.2$ & $370,021.0$ \\
\hline 19 & 1994-02-14 & $18,059.9$ & $313,187.0$ \\
\hline 20 & $1994-02-15$ & $18,799.3$ & $327,258.0$ \\
\hline 21 & $1994-02-17$ & $19,059.2$ & $411,578.0$ \\
\hline 22 & $1994-02-21$ & $19,358.3$ & $371,871.0$ \\
\hline 23 & 1994-02-22 & $19,641.0$ & $234,557.0$ \\
\hline 24 & 1994-02-24 & $19,802.2$ & $391,120.0$ \\
\hline 25 & $1994-02-28$ & $20,196.0$ & $316,321.0$ \\
\hline 26 & 1994-03-01 & $20,275.6$ & $248,701.0$ \\
\hline 27 & 1994-03-03 & $19,996.9$ & $302,713.0$ \\
\hline 28 & 1994-03-07 & $20,360.7$ & $279,017.0$ \\
\hline 29 & 1994-03-08 & $20,760.3$ & $258,385.0$ \\
\hline & $\begin{array}{l}\text { Arithmetic } \\
\text { means: }\end{array}$ & $16,902.0$ & $298,485.8$ \\
\hline $\begin{array}{l}\text { Correlation } \\
\text { coefficient }\end{array}$ & 0.4514567 & & Squares \\
\hline $\begin{array}{c}\text { Volume } \\
\text { variance }\end{array}$ & $6,703,766,931$ & $6,703,766,931$ & $4.49 \times 10^{19}$ \\
\hline $\begin{array}{c}\text { Co-variance } \\
\text { (WIG, volume) }\end{array}$ & $91,547,424.2$ & \multicolumn{2}{|c|}{$\begin{array}{c}\text { Reynolds number }= \\
8.38 \times 10^{15}\end{array}$} \\
\hline $\begin{array}{c}\tan \alpha=\text { directional } \\
\text { coefficient of } \\
\text { regression function }\end{array}$ & 0.013656117 & 0.013656117 & 0.000186 \\
\hline
\end{tabular}

For the data from the first period, lasting from 199401-03 to 1994-03-08, the following Reynolds numbers were calculated:

$R_{e}(1994-03-03)=1.93 \times 10^{16}$,

$R_{e}(1994-03-07)=1.24 \times 10^{16}$,

$R_{e}(1994-03-08)=8.38 \times 1^{15}$.

The WIG index on 1994-03-03 reached the value of 19,996.9 with the turnover of 302,713. The Reynolds warning rate had the highest value in the examined period of $R_{e}(1994-03-03)=1.93 \times 10^{16}$. In a subsequent day of listings of the WIG index at the Warsaw Stock Exchange, i.e. 1994-03-07, both the index and the
Reynolds number for WIG index calculated in the period from $1995-02-16$ to $1995-03-28$.

\begin{tabular}{|c|c|c|c|}
\hline Item & $\begin{array}{c}\text { Date } \\
(Y Y Y Y-M M-D D) \\
\end{array}$ & WIG & Volume \\
\hline 1 & $1995-02-16$ & $6,725.9$ & 25,831 \\
\hline 2 & $1995-02-17$ & $6,725.5$ & 27,511 \\
\hline 3 & $1995-02-20$ & $6,599.6$ & 21,347 \\
\hline 4 & $1995-02-21$ & $6,277.2$ & 49,337 \\
\hline 5 & $1995-02-22$ & $6,246.7$ & 28,591 \\
\hline 6 & $1995-02-23$ & $6,419.8$ & 24,402 \\
\hline 7 & $1995-02-24$ & $6,903.4$ & 81,474 \\
\hline 8 & $1995-02-27$ & $6,604.0$ & 26,367 \\
\hline 9 & $1995-02-28$ & $6,447.3$ & 19,211 \\
\hline 10 & 1995-03-01 & $6,460.2$ & 14,985 \\
\hline 11 & 1995-03-02 & $6,541.0$ & 15,065 \\
\hline 12 & 1995-03-03 & $6,698.9$ & 36,089 \\
\hline 13 & 1995-03-06 & $6,720.0$ & 22,701 \\
\hline 14 & 1995-03-07 & $6,668.5$ & 25,507 \\
\hline 15 & 1995-03-08 & $6,662.3$ & 18,079 \\
\hline 16 & 1995-03-09 & $6,661.6$ & 20,774 \\
\hline 17 & 1995-03-10 & $6,561.5$ & 23,943 \\
\hline 18 & 1995-03-13 & $6,521.9$ & 22,127 \\
\hline 19 & 1995-03-14 & $6,347.9$ & 19,932 \\
\hline 20 & 1995-03-15 & $6,352.6$ & 16,477 \\
\hline 21 & $1995-03-16$ & $6,282.0$ & 22,344 \\
\hline 22 & 1995-03-17 & $6,210.3$ & 21,076 \\
\hline 23 & 1995-03-20 & $6,153.7$ & 16,216 \\
\hline 24 & 1995-03-21 & $6,069.6$ & 17,609 \\
\hline 25 & 1995-03-22 & $5,977.1$ & 20,703 \\
\hline 26 & $1995-03-23$ & $5,922.1$ & 20,094 \\
\hline 27 & 1995-03-24 & $5,949.5$ & 18,501 \\
\hline 28 & $1995-03-27$ & $6,070.5$ & 21,114 \\
\hline 29 & $1995-03-28$ & $5,904.7$ & 24,868 \\
\hline & $\begin{array}{l}\text { Arithmetic } \\
\text { means: }\end{array}$ & $6,402.9$ & $24,906.1$ \\
\hline $\begin{array}{l}\text { Correlation } \\
\text { coefficient }\end{array}$ & 0.366918476 & & Squares \\
\hline $\begin{array}{c}\text { Volume } \\
\text { variance }\end{array}$ & $164,479,148.5$ & $164,479,148.5$ & $2.705 \times 10^{16}$ \\
\hline $\begin{array}{c}\text { Co-variance } \\
\text { (WIG, volume) }\end{array}$ & $1,285,733.074$ & \multicolumn{2}{|c|}{$\begin{array}{c}\text { Reynolds number }= \\
1.65311 \times 10^{12}\end{array}$} \\
\hline $\begin{array}{l}\tan \alpha=\text { directional } \\
\text { coefficient of } \\
\text { regression function }\end{array}$ & 0.007816997 & 0.007816997 & $6.111 \times 10^{-5}$ \\
\hline
\end{tabular}

turnover revealed a growing trend. At the same time, the Reynolds number decreased to the level of $R_{e}$ (1994$03-07)=1.24 \times 10^{16}$. On a subsequent day, the stock exchange started a long bear market period. While treating $R_{e}$ as a warning rate, in this case we can claim that the warning concerning the change of the stock exchange trend occurred two days in advance.

In the second period under analysis, lasting from 199502-16 to 1995-03-28, the situation was slightly different. The following values of Reynolds warning rate were obtained: 
$R_{e}(1995-03-23)=1.12249 \times 10^{12}$,

$R_{e}(1995-03-24)=1.34683 \times 10^{12}$,

$R_{e}(1995-03-27)=1.67597 \times 10^{12}$,

$R_{e}\left(\mathbf{1 9 9 5 - 0 3 - 2 8 )}=1.65311 \times 10^{12}\right.$,

$R_{e}(1995-03-29)=1.74399 \times 10^{12}$,

$R_{e}(1995-03-30)=1.60058 \times 10^{12}$.

In this case, the change in market trend on 199503-28 should be interpreted in a slightly different way. The value of WIG index and turnover observed on 1995$03-28$ were $5,904.7$ and 24,868 , respectively. The value of the Reynolds rate was $R_{e}(1995-03-28)=1.65311 \times 10^{12}$. On subsequent days of listings, both the values of the WIG index and the turnover were already lower. In the time period under analysis, the highest value of the stockexchange Reynolds number $R_{e}(1995-03-29)=1.74399 \times$ $10^{12}$ was observed just after the change of the market growing trend. In this specific case, the nature of the stock-exchange Reynolds number changed from a warning to a confirmation. This means that in later periods the values of the stock-exchange Reynolds number were much lower than the maximum value falling on 1995-0329 . Therefore, a change in the market trend of 1995-0328 is interpreted in a slightly different way. In this case, the confirming character of the stock-market Reynolds number is understood as confirmation of a change in the existing market trend.

The forecasting possibilities of an economic equivalent of the Reynolds number show that it stand a chance to become an important element of investment strategies applied in the stock market game. Because of its usefulness, this tool could be used both by small investors and institutional investors.

\section{Conclusions}

This article presents an analysis of the rotational dynamics of market movement observed in space $\boldsymbol{R}_{+}^{3}=$ $P \times Q \times T$. Variables in the time model $\boldsymbol{R}_{+}^{3}$ are values of WIG index $(P)$ and volume $(Q)$, which form spiral stockexchange trajectories. The research revealed that the observed three-dimensional market trajectory is common not only for stock exchange indices, but also for all types of stocks. It turns out that all two-dimensional graphs representing price changes in time (or volume changes in time) emerge as a result of orthogonal projection of a three-dimensional curve (rotational-spiral trajectory) on an appropriate plane. The movement made by the market in $\boldsymbol{R}_{+}^{3}$, is of a rotational-spiral type. The analysis of three-dimensional stock-exchange models allows the same time relations between the price and the volume to be followed. Additionally, it is possible to perceive a similarity of rotational-spiral curves, created as a result of stock exchange movements, to the movement which is created in hydrodynamic models. A similarity of those two different dynamical systems is not related to factors that cause this movement, but to the type of the movement itself (logical homology). The value of stock exchange number $R_{e}$ (determined, e.g. for a specific index) can be calculated as a product of variance and the square of velocity. At the moment when number $R_{e}$ reaches high values, the movement previously described as laminar develops into a turbulent one. Observed stock exchange rotational and spiral movement, consisting in market transition from a state of stable dynamics into a turbulent market, is a rapid change of a laminar movement into a turbulent movement. Such situations often occur on financial markets, where events seemingly of little importance have such a strong impact on the reactions of market participants that a very fast mood change occurs, resulting in the emergence of stock-exchange turbulence and a market collapse.

\section{References}

[1] H. Poincaré, Sur le problème des trois corps et les équations de la dynamique, in: Oeuvres de Henri Poincaré, Vol. VII: Masses fluides en rotation. Principes de mécanique analytique. Problème des trois corps, Gauthier-Villars, Paris 1952, p. 262.

[2] L. Bachelier, Théorie de la spéculation, in: Annales scientifiques de l'Ecole Normale Supérieure, 3e série, Vol. 17, Gauthier-Villars, Paris 1900, p. 21.

[3] A. Papoulis, S.U. Pillai, Probability, Random Variables, and Stochastic Processes, 4th ed., McGraw-Hill, Boston 2002.

[4] M. Smoluchowski, in: Pisma Marjana Smoluchowskiego z polecenia Polskiej Akademii Umiejętności zgromadzone $i$ wydane przez Wtadysława Natansona, Vol. 2, Drukarnia Uniwersytetu Jegiellońskiego, Kraków 1927, p. 268.

[5] J. Barrow-Green, Poincaré and the Three Body Problem, American Mathematical Society, Providence 1997.

[6] J. Mawhin, Henri Poincaré, Notices Amer. Math. Soc. 52, 1036 (2005).

[7] M. Tempczyk, Teoria chaosu dla odważnych, Wydawnictwo Naukowe PWN, Warszawa 2002.

[8] H. Lamb, Hydrodynamics, 6th ed., Cambridge University Press, Cambridge 1993.

[9] O. Reynolds, Papers on Mechanical and Physical Subjects, Reprinted from Various Transactions and Journals, Vol. 1: 1869-1882, Cambridge University Press, Cambridge 1900.

[10] O. Reynolds, Papers on Mechanical and Physical Subjects, Reprinted from Various Transactions and Journals, Vol. 2: 1881-1900, Cambridge University Press, Cambridge 1901.

[11] O. Reynolds, Papers on Mechanical and Physical Subjects, Vol. 3: The Sub-Mechanics of the Universe, Cambridge University Press, Cambridge 1903.

[12] R.B. Bird, W.E. Stewart, E.N. Lightfoot, Transport Phenomena, Revised 2nd Ed., John Wiley \& Sons, New York 2007.

[13] J. Happel, H. Brenner, Low Reynolds Number Hydrodynamics: With Special Applications to Particulate Media, Martinus Nijhoff Publishers, The Hague 1983.

[14] B.M. Jaworski, A.A. Piński, Elementy fizyki, Vol. 1: Ruch i sity; prawa zachowania; kinetycznocząsteczkowa teoria gazów; sity molekularne $i$ stany skupienia materii, wyd. 2, Państwowe Wydawnictwo Naukowe, Warszawa 1979. 
[15] R.N. Mantegna, H.E. Stanley, Ekonofizyka. Wprowadzenie, Wydawnictwo Naukowe PWN, Warszawa 2001.

[16] R. Antoniewicz, Metoda najmniejszych kwadratów dla zależności niejawnych $i$ jej zastosowania $w$ ekonomii, Prace Naukowe Akademii Ekonomicznej we Wrocławiu nr 445, Akademia Ekonomiczna im. O. Langego we Wrocławiu, Wrocław 1988.

[17] J. Juzwiszyn, Wiry ekonomiczne $i$ fale R.N. Elliotta, Katedra Matematyki i Cybernetyki, Wydział Zarządzania i Informatyki, Akademia Ekonomiczna im. Oskara Langego, Wrocław 2006.

[18] A. Jakimowicz, Źródła niestabilności struktur rynkowych, Seria: Współczesna Ekonomia, Wydawnictwo Naukowe PWN, Warszawa 2010.

[19] J. Juzwiszyn, O obrotach sfer finansowych, in: Ekonomia Matematyczna, No. 5, Wydawnictwo Akademii Ekonomicznej im. O. Langego we Wrocławiu, Wrocław 2001, p. 133.

[20] A. Smoluk, Normy, prawa nauki i fale Elliotta, in: Ekonomia Matematyczna, No. 6, Wydawnictwo Akademii Ekonomicznej im. O. Langego we Wrocławiu, Wrocław 2002, p. 11.

[21] A. Smoluk, Mathematical Economics 9, 31 (2005).

[22] F. Leja, Geometria analityczna, wyd. 3, PWN, Warszawa 1961.

[23] A. Jakimowicz, J. Juzwiszyn, Acta Phys. Pol. A 121, B-54 (2012).

[24] R.P. Feynman, R.B. Leighton, M. Sands, Feynmana wyktady $z$ fizyki, Vol. 1.1, 1.2, Wydawnictwo Naukowe PWN, Warszawa 2014.
[25] J. Juzwiszyn, Mathematical Economics 6, 49 (2010).

[26] J. Juzwiszyn, Mathematical Economics 2, 75 (2005).

[27] J. Tinbergen, Zeitschrift für Nationalökonomie 1669 (1930).

[28] U. Ricci, Zeitschrift für Nationalökonomie 1, 649 (1930).

[29] H. Schultz, Der Sinn der statistischen Nachfragekurven, in: Veröffentlichungen der Frankfurter Gesellschaft für Konjunkturforschung, Heft 10, Ed. E. Altschul, Kurt Schroeder Verlag, Bonn 1930.

[30] A. Hanau, Die Prognose der Schweinepreise, in: Vierteljahrshefte zur Konjunkturforschung herausgegeben vom Institut für Konjunkturforschung, Sonderheft 7, Verlag von Reimar Hobbing, Berlin 1928, p. 4.

[31] L. Walras, Éléments d'économie politique pure, ou Théorie de la richesse sociale, Éd. définitive, revue et augmentée par l'auteur, R. Pichon et R. DurandAuzias, Paris 1926

[32] A. Marshall, Principles of Economics. An Introductory Volume, Macmillan, London 1947.

[33] R.G.D. Allen, Ekonomia matematyczna, PWN, Warszawa 1961.

[34] D. Glycopantis, N.C. Yannelis, (Eds.), Differential Information Economies, Springer-Verlag, Berlin 2005.

[35] L. von Bertalanffy, Ogólna teoria systemów. Podstawy, rozwój, zastosowania, PWN, Warszawa 1984. 